\title{
Study on the Technological Innovation Capability of Colleges and Universities in Heilongjiang Province-Based on the Patent Analysis
}

\author{
Zhili He and Hui Zhang* \\ School of Law, Daqing Normal University, Daqing 163712, China \\ ${ }^{*}$ Corresponding author
}

\begin{abstract}
According to the data 2010-2016 published by the State Intellectual Property Office and the patent data of Heilongjiang Intellectual Property Office, this paper analyses the patent output capacity of Heilongjiang universities and its contribution to the whole province's patent output. Based on the three dimensions of patent output, patent type and patent composition, this paper analyzes the patent situation of 15 representative universities and concludes the fields' distribution of technological innovation ability of each university. Finally, from the two levels of government and universities, it summarizes the existing problems in the innovation of colleges and universities of in Heilongjiang and puts forward the countermeasures.
\end{abstract}

Keywords-patent analysis; innovation ability; colleges and universities in Heilongjiang; countermeasure

\section{INTRODUCTION}

With the rapid development of science and technology innovation, the competition of science and technology among the countries and among the regions also becomes increasingly fierce. The improvement of scientific and technological innovation has become an important weapon for a country or a region to become one of the advanced countries or regions in the world [1]. Colleges and universities are not only important forces in knowledge innovation, but also the key body of technological innovation and development. In recent years, the state and local governments are also increasingly aware of the important role of universities' science and technology innovation in regional economic development. Relevant policies have been promulgated to support the innovation development of colleges and universities and improve the innovation capability of colleges and universities so as to promote the overall innovation capability of the region and stimulate economic growth." Significantly improve the intellectual property application level" of the main objective of "Heilongjiang Provincial Implementation of Intellectual Property Strategic Action Plan (2015-2020)" puts forward that it is necessary to rapidly upgrade the degrees of implementation transformation and industrialization of intellectual property of enterprises, universities and research institutes in Heilongjiang Province from 2015 to 2020 and initially establishes intellectual property investment and financing system, to promote economic and social development and help to benefit the Heilongjiang economy. Heilongjiang colleges and universities have played an important role in producing intellectual property and revitalizing Heilongjiang economy and have been given an important mission.

In order to comprehensively understand the capability of science and technology innovation of universities in Heilongjiang Province, this paper analyzes universities' patent output in the past 10 years (2010-2016) as aim. On the basis of a comprehensive analysis of the patent output of colleges and universities in the province, this paper chooses fifteen universities as research sample, which are Harbin Institute of Technology (HIT), Harbin Engineering University (HEU), Northeast Forestry University (NFU), Heilongjiang University (HLJU), Harbin Medical University (HMU), Northeast Agricultural University (NAU), Harbin University of Science and Technology (HUST), Northeast Petroleum University (NEPU), Heilongjiang University Of Chinese Medicine (HLJUCM), Heilongjiang University of Science and Technology (USTH), Qiqihar University (QU), Heilongjiang Bayi Agricultural University(HBAU), Jiamusi University (JU), Heilongjiang Institute of Technology (HIT) and Suihua University (SU), and then carries out detailed analysis. These 15 colleges and universities include science and technology, agriculture, forestry and medicine from the genre, covering five regions of Harbin, Daqing, Qiqihar, Jiamusi and Suihua from a geographical perspective, which can reflect the innovation ability of colleges and universities in Heilongjiang Province to a certain extent. With the publication and statistics data of the State Intellectual Property Office of the People's Republic of China and the statistical data of the Intellectual Property Office of Heilongjiang Province as the data sources, we obtained the relevant patents information of the above 15 universities. With the help of analysis tools such as Origin and Excel, this paper evaluates the innovation capacity of Heilongjiang universities, to find out the problems exists in the innovation of colleges and universities and put forward corresponding countermeasures and suggestions.

\section{ANALysis OF THE OVERALl PATENT APPLICATION of UNIVERSITIES IN HEILONGJIANG PROVINCE}

\section{A. Patent Output Analysis}

Figure 1 shows the trend of patent applications in Heilongjiang Province during 2010-2016. As can be seen from Figure 1, the total number of patent applications in Longjiang colleges and universities is on the quick rise. In 2010, the total number of applications was 2920 and the total number of 
applications in 2011 was 4233, an increase of 45\%; in 2012, the total number of applications was 6871, an increase of $135 \%$; in 2016 it rose to 18,662, an increase of 306\%. It indicates that the patent yield capacity of colleges and universities in Heilongjiang Province develops rapidly, which is closely related to the continuous increase of scientific research support from nation and Heilongjiang province. In addition, the improvement of the intellectual property policy environment in Heilongjiang Province also plays an important role in promoting the work of intellectual property in colleges and universities. As can also be seen from Figure 1, in 2010-2016, the patent applications of invention patents and utility model patents in Heilongjiang universities' patent output all showed a rapid upward trend. Among them, the number of invention patent applications in 2010 was 1,980 and in 2016 it rose to 5305, an increase of $168 \%$; utility model applications in 2010 was 506, and the number in 2016 was 5618, an increase of $1010 \%$, utility model applications quantity increase was far greater than that of the invention patents. The growth rate of design patents is relatively small, with a total of 434 applications in 2010 and 939 in 2016, an increase of only 116\% in seven years.

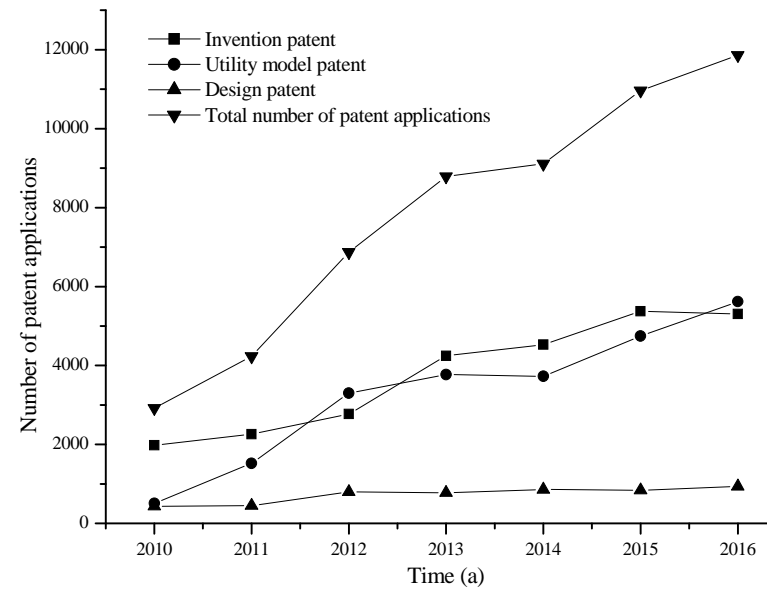

FIGURE I. PATENT APPLICATION CHANGES CHART OF HEILONGJIANG UNIVERSITIES

\section{B. Contributions of University Patents to Patents of the Whole Province}

Figure 2 shows the contribution analysis of Heilongjiang Universities' patents to those of the whole province. It can be seen from Figure 2 that in 2010-2016, the proportion of invention patents in universities in 2011 accounting for less than $20 \%$ of invention patents in the whole province in 2011 was only $18.1 \%$, while were all higher than $20 \%$ in the other years. The proportions in 2015 and 2016 rose to 31.7\% and $33.6 \%$ respectively, indicating that the innovation of colleges and universities in Heilongjiang Province plays an important role in the province's knowledge and technological innovation.

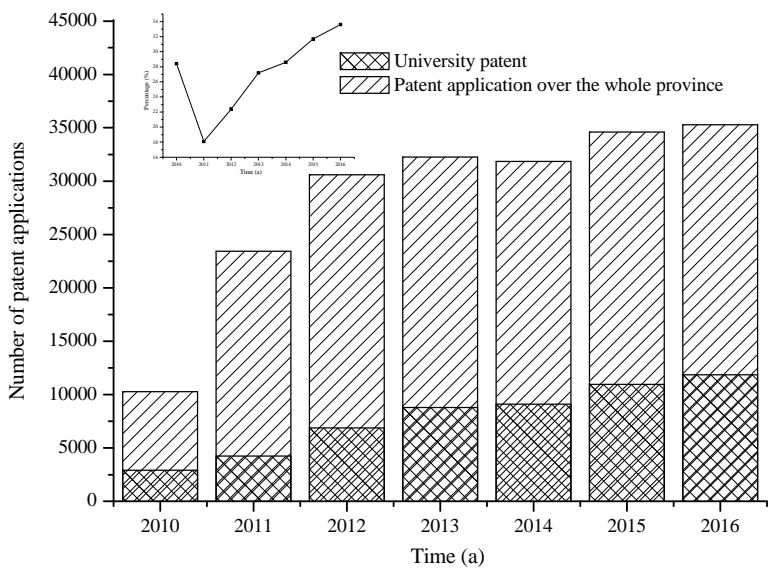

FIGURE II. CONTRIBUTIONS ANALYSIS OF HEILONGJIANG UNIVERSITIES' PATENTS TO PATENTS OF THE WHOLE PROVINCE

\section{PATENT ANALYSIS OF INDIVIDUAL UNIVERSITY IN HEILONGJIANG}

\section{A. Patent Output Analysis of 15 Universities}

The patent output of 15 representative universities in Heilongjiang Province from 2010 to 2016 is shown in Table 1. From Table 1, it can be seen that the overall composition of 15 university patents (2010-2016): the total number is 56,191, of which invention patents account for $52.81 \%$ and utility models account for $25.70 \%$. In comparison, the number of designs is small, only Accounting for $3.46 \%$, the number of patents granted in seven years was $18.03 \%$ of the total. The analysis of data shows that the design patent is not the key point of work in Heilongjiang universities. And their patents mainly focused on inventions and utility models. Licensed patent ratio is low, less than $20 \%$, indicating that technical content of Heilongjiang universities' science and technology innovation is low, this result also leads to the deficiencies of patent conversion application. And this also causes that intellectual property rights can not be better protected. Circumstances are different while we analyse individual university. These 6 universities' invention patents proportion are higher, which are Harbin Institute of Technology, Harbin Engineering University, Northeast Forestry University, Heilongjiang University, Northeast Agricultural University, Harbin Polytechnic University. It indicates that these 6 universities' technological innovation level is relatively high. While for those 5 universities, Harbin Engineering University, Heilongjiang University, Harbin Polytechnic University, Qiqihar University and Jiamusi University, there exists a higher number of utility model patents. And it indicates that those 5 universities focus on the improvement innovation of existing application technology. 
TABLE I. PATENT OUTPUT ANALYSIS OF 15 UNIVERSITIES (2010-2016)

\begin{tabular}{|c|c|c|c|c|c|}
\hline \multirow{2}{*}{ Universities } & \multirow{2}{*}{$\begin{array}{l}\text { Authorization pieces of } \\
\text { invention patent }\end{array}$} & \multicolumn{3}{|c|}{ Types of patent } & \multirow{2}{*}{ Total } \\
\hline & & Invention & Utility model & Industrial design & \\
\hline HIT & 5358 & 15311 & 556 & 15 & 21240 \\
\hline HEU & 1809 & 5619 & 1026 & 215 & 8669 \\
\hline NFU & 406 & 1248 & 932 & 383 & 2969 \\
\hline HLJU & 815 & 2009 & 1304 & 86 & 4214 \\
\hline HMU & 127 & 272 & 221 & 4 & 624 \\
\hline NAU & 471 & 1469 & 659 & 12 & 2611 \\
\hline HUST & 376 & 1491 & 2845 & 781 & 5493 \\
\hline NEPU & 247 & 643 & 2083 & 31 & 3004 \\
\hline HLJUCM & 45 & 106 & 35 & 11 & 197 \\
\hline USTH & 94 & 300 & 869 & 82 & 1345 \\
\hline QU & 103 & 419 & 1008 & 121 & 1651 \\
\hline HBAU & 127 & 445 & 493 & 27 & 1092 \\
\hline $\mathrm{JU}$ & 47 & 198 & 1294 & 6 & 1545 \\
\hline HLJIT & 92 & 92 & 846 & 149 & 1179 \\
\hline SU & 13 & 54 & 270 & 21 & 358 \\
\hline Total & 10130 & 29676 & 14441 & 1944 & 56191 \\
\hline Percentage (\%) & 18.03 & 52.81 & 25.70 & 3.46 & \\
\hline
\end{tabular}

\section{B. 15 Universities' IPC Analysis of Patents}

According to the International Patent Classification (IPC classification), the patent structure of 15 universities is summarized as shown in Table 2. It can be seen that the patent applications of 15 universities cover 8 departments of the entire patent field and the strong areas are located in the three departments of department $\mathrm{H}$ (electrical technology), department B (operation and transportation), department C (chemical and metallurgy), followed by Part A (Essential agriculture, light industry, and medicine) and F (mechanical engineering, lighting and heating), the weak areas are E (fixed buildings) and $\mathrm{D}$ (textile and paper), especially $\mathrm{D}$, patent output less than 600 pieces.

TABLE II. 15 UNIVERSITIES’ PATENTS IPC COMPOSITION (2010-2016)

\begin{tabular}{|c|c|c|c|c|c|c|c|c|}
\hline \multirow{2}{*}{ University Names } & \multicolumn{8}{|c|}{ IPC } \\
\hline & A & B & $\mathrm{C}$ & D & $\mathbf{E}$ & $\mathbf{F}$ & G & $\mathbf{H}$ \\
\hline HIT & 872 & 4589 & 4482 & 254 & 616 & 1473 & 6936 & 4659 \\
\hline HEU & 413 & 1225 & 754 & 25 & 227 & 1375 & 3651 & 1174 \\
\hline NFU & 617 & 736 & 761 & 92 & 126 & 96 & 494 & 81 \\
\hline HLJU & 1041 & 729 & 1325 & 78 & 146 & 160 & 1044 & 487 \\
\hline $\mathrm{HMU}$ & 505 & 23 & 154 & 0 & 0 & 1 & 84 & 12 \\
\hline NAU & 1471 & 220 & 944 & 1 & 49 & 87 & 310 & 31 \\
\hline HUST & 523 & 1528 & 517 & 41 & 142 & 378 & 1990 & 1091 \\
\hline NEPU & 343 & 601 & 438 & 5 & 674 & 327 & 1013 & 170 \\
\hline HLJUCM & 150 & 6 & 26 & 0 & 0 & 0 & 25 & 4 \\
\hline USTH & 101 & 262 & 157 & 2 & 134 & 84 & 500 & 142 \\
\hline QU & 280 & 311 & 269 & 63 & 35 & 49 & 543 & 78 \\
\hline HBAU & 492 & 124 & 262 & 3 & 21 & 29 & 189 & 23 \\
\hline $\mathrm{JU}$ & 595 & 377 & 95 & 14 & 44 & 57 & 325 & 38 \\
\hline HLJIT & 141 & 196 & 47 & 1 & 91 & 60 & 432 & 82 \\
\hline SU & 86 & 66 & 22 & 1 & 3 & 9 & 112 & 20 \\
\hline Total & 7630 & 10993 & 10253 & 580 & 2308 & 4185 & 17648 & 8092 \\
\hline
\end{tabular}




\section{Problems in the InNovation of Science and TECHNOLOGY IN COLLEGES AND UNIVERSITIES}

\section{A. The Number of Core Patents is Small and that Number of} the Idle Ones is Big

Ministry of Education statistics show that the total number of patent applications of China's colleges and universities in 1986-1992 was less than 2000, and as of 2008 reached 45,000, accounting for nearly $3.6 \%$ of the total number of patent applications. The patent applications amount of colleges and universities to 2016 reached 184423 , accounting for $13.7 \%$ of the total number of patent applications. University patents in Heilongjiang in 2016 accounted for 33.6\% of the province's patent, much higher than the national average. It can be said that universities are important contributors of Heilongjiang Province's patent output. But the quality is generally low, the core patent amount is particularly small, the core patents amount which can form patent portfolio is particularly small. And it is difficult to provide the necessary technical system and intellectual property rights for Heilongjiang's economic restructuring and upgrading of industrial technology. Moreover, most of university patents originate from scientific research projects, and the majority of projects are basic research. And this leads to the university's emphasis of theory in the patent field and further makes theoretical model part of a patent. Of course, it causes that most of patents can not be applied to the production, resulting in the majority of the patent idle.

\section{B. System is Not Sound Enough and the Distribution of Rights and Interests is Uneven}

System imperfection embodies in the internal and external levels. The internal level of colleges and universities is reflected in their imperfect scientific research management system. There exists imperfect system of cognizance of patent results, and the patents examination basically only considers the number of patent applications. As a result, inventors blindly pursue patent applications quantity and ignore the promotion of patents quality. In addition, in the process of promotion of title, the main focus is basically on the quantity and the award-winning, ignoring the transformation of the achievements and the achievements of promotion staff, and reducing the enthusiasm of promotion staff. The external aspect is reflected in the unreasonable provisions of rights and interests distribution system of service inventions in our country. The unequal distribution of rights and interests in service inventions leads to the inventor's lack of motivation, especially the motivation of patent transformation. This also causes that he patent output does not match with the social needs. And this further aggravates the idleness of patents, which makes it difficult that the patents can be applied in the process of economic construction in Heilongjiang.

\section{Countermeasure Analysis on Promoting the INNOVATION ABILITY OF SCIENCE AND TECHNOLOGY IN COLLEGES AND UNIVERSITIES}

A. Strengthen the Cultivation and Protection of High-value Patents in Colleges and Universities and Strengthen the Patent Transformation

High-value patents refer to patents those are not only of high technical level but also an important lead in the technological advancement of the industry [2]. High-value patent cultivation is very complex system engineering. The research results should solve the key technology or core technology which is urgently needed or needed to be resolved. And through high-value patents, promote high-value products production, high-value industries development, and high-value market growth. In addition, we should pay attention to the protection of high-value patents. For colleges and universities, to strengthen the protection of high-value patents, it is necessary to have the government's attention, improve the system, and to increase the inventor's awareness of patent protection. The ultimate goal of the invention is to serve the society and promote social and economic development by transformation and application. Therefore, a patent promotion mechanism for patent transformation should be established. The university patent transformation promotion mechanism is a diversified system, and the content should be comprehensive rather than single [3]. Heilongjiang universities patent transformation should be combined with Heilongjiang regional economy and the characteristics of universities in order to build a sound mechanism to ensure universities patent be effectively transformed into productive forces and promote economic growth of Heilongjiang. First of all, colleges and universities should develop appropriate policies, and focus on the support of scientific projects with potential mainly from the funds, scientific research staffing so as to enhance the output of high-level patents. Secondly, according to the situation disciplines, colleges and universities should screen patent has been applied for so as to be converted for applications and prevent the loss of patents. Thirdly, for the balance of patent transformation and scientific research, it is necessary to incorporate the transformation of invention patent into the consideration of scientific research work. Promotion of title or reward should reflect the recognition to the results transformation personnel, and colleges and universities should take a variety of ways to stimulate the transformation of patents. Fourth, colleges and universities, if possible, can set up foundations to promote or transform the results, as well as set up bases, effectively to convert the scientific and technological achievements into productive forces.

\section{B. Improving the Service Invention System and Reward Incentive System in Colleges and Universities}

Colleges and Universities are very important science and technology R \& D organizations in China, with the legal positioning of the public and the intensity of $\mathrm{R} \& \mathrm{D}$ personnel, so its service invention has its own particularity. The main purpose of patent legislation is to encourage inventions, so as to promote the progress and development of science and technology [4]. Taking into account the special attributes of the university and the characteristics of body, colleges and 
universities should not adhere to the principle that the right of service patent should belong to organizations, but should carry out special provisions on the ownership of the invention rights of the university and assign the right to the appropriate subject which can maximize the value of patent with the principle of improving the quality and the application of patent in colleges and universities. It is important to note that the patent for the invention of state-supported scientific research projects should be given priority to the project. The right of patent should be given to the inventor if the organization does not choose to keep the right. And that will be beneficial for reducing or removing the barrier of state-owned projects patent conversion [5].

\section{REFERENCES}

[1] Y. Guo, B. Wang. Study on the Economic Growth of Patent Output in the High-tech Industry [J]. Journal of Management \& Sustainability. 3 (2012)103-107.

[2] G. Dominique, V. Bruno. Applications, grants and the value of patent [J] Economics Letters. 69(2000)109-114.

[3] E. Einer, Do patent holdup and royalty stacking lead to systematically excessive royalties [J]. Journal of Competition \& Economics. 4(2008)535-570.

[4] L. Dan, M.A. Lemley. Policy Levers in Patent Law [J]. Virginia Law Review. 89(2003)1575-1696.

[5] R.M. Wang, Q. Teng, F.F. Lu. The analysis on the factors affecting the transformation of patents in university and the countermeasures [J]. Science Research Management. 34 (2013) 137-144. 